\title{
PENINGKATAN KUALITAS PRODUK PADA MESIN PRODUKSI NONWOVEN SPUNBOND DENGAN MENGGUNAKAN METODE SEVEN TOOLS DAN FMEA
}

\author{
Mochammad Damaindra, Atikha Sidhi Cahyana \\ Program studi Teknik Industri \\ Universitas Muhammadiyah Sidoarjo, Sidoarjo, Jawa Timur 61271 \\ viendraeric@gmail.com; atikhasidhi@umsida.ac.id
}

\begin{abstract}
Abstrak
PT. XYZ merupakan perusahaan yang berkembang dibidang Nonwoven Spunbond, produk yang dihasilkan yaitu kain plastik terbuat dari biji plastik polypropylene. Produk spunbond bisa diaplikasikan pada spring bed kemudian tas, jaket serta masker. Standart kualitas yang ditentukan diantaranya tidak ada cacat produk berupa lubang (hole), bintik polimer (drop) yang menempel pada produk diakibatkan kegagalan transformasi dan tidak ada sobek pada sisi produk yang mengakibatkan bertambahnya reject potongan sisi produk (trim).Penelitian ini menggunakan metode seven tools untuk mengetahui faktor penyebab tingginya reject yang mengakibatkan pemborosan material. kemudian penyelesaiannya menggunakan metode Failure Mode and Effect Analyis (FMEA) untuk memberikan usulan perbaikan pada bentuk kegagalan tertinggi yang diperoleh melalui perhitungan nilai RPN.Dari hasil analisa didapatkan reject tertinggi yaitu jenis reject trim yang dipengaruhi oleh beberapa faktor yaitu pegawai baru, order yang bervariasi, metode berdasarkan type mesin lama, kualitas material, desain mesin yang tidak sesuai order. Dari analisa dan perhitungan SOD diperoleh nilai RPN tertinggi yaitu 30 ada pada lebar kain berlebih yang menyebabkan tingginya reject trim. Rekomendasi perbaikan yang diberikan yaitu membuat alat bantu penutup plat tembaga/kuningan untuk menutup sisi samping spinneret dan membuat SOP serta evaluasi kinerja sebagai tahap control.
\end{abstract}

Kata Kunci: Spunbond, Seven Tools, FMEA.

\section{PENDAHULUAN}

PT. XYZ merupakan perusahaan yang berkembang dibidang Nonwoven Spunbond, produk yang dihasilkan yaitu kain plastik terbuat dari biji plastik polypropylene. Untuk dapat bersaing dipasaran perusahaan mengutamakan kualitas produk yang dihasilkan dimana pengoptimalan proses produksi menjadi faktor yang harus mendapatkan perhatian khusus, sehingga dapat menghasilkan produk yang memenuhi standart kualitas yang ditentukan.

Hasil proses produksi bulan agustus sampai oktober 2015 menunjukkan total reject yang dihasilkan melebihi toleransi yang ditentukan,Toleransi untuk reject filamen sebesar $2 \%$, kain $2 \%$, dan reject trim $2 \%$ dari total produksi. Besarnya reject dikarenakan adanya kendala dibeberapa proses produksi. Pada beberapa proses produksi yang sering mengakibatkan produk reject yaitu pada saat peleburan (melting), pendinginan (cooling), dan pengepresan. Untuk itu pengendalian kualitas sangatlah penting, langkah awal dalam melakukan pengendalian kualitas yaitu dengan mencari jenis-jenis cacat yang terjadi dan penyebabnya menggunakan seven tools kemudian penyelesaiannya menggunakan metode FMEA (Failure Mode and Effect Analyis).Metode FMEA bertujuan mengidentifikasi dan menilai resiko-resiko yang berhubungan dengan potensi kegagalan dimana potensi kegagalan merupakan variabel-variabel bebas yang teridentifikasi mengakibatkan produk cacat.tinggi, akibatnya terjadi pemborosan pada material.

\section{LANDASAN TEORI}

\section{A. Konsep Peningkatan Kualitas}

Peningkatan kualitas merupakan aktifitas teknik dan manajemen yang diawali dengan mengukur karakteristik kualitas dari produk tersebut kemudian membandingkan hasil pengukuran itu dengan spesifikasi produk yang diinginkan pelanggan, serta mengambil tindakan peningkatan yang tepat apabila ditemukan perbedaan di antara 
kinerja aktual dan standar (Gaspersz, 2003). Sehingga dapat disimpulkan bahwa peningkatan kualitas lebih memfokuskan pada peningkatan proses produksi, guna memenuhi kebutuhan pelanggan. Menurut Gaspersz (2003), pengertian kualitas dalam konteks peningkatan proses adalah bagaimana baiknya kualitas suatu produk (barang dan/atau jasa) itu memenuhi spesifikasi dan toleransi yang ditetapkan oleh bagian desain dan pengembangan dari suatu perusahaan.

\section{B. Metode Seven Tools}

Seven tools yaitu tujuh alat bantu yang bermanfaat untuk memetakan lingkup persoalan, menyusun data dalam diagram-diagram agar lebih mudah untuk dipahami, menelusuri berbagai kemungkinan penyebab persoalan dan memperjelas kenyataan dalam suatu persoalan.Tujuh alat bantu dalam seven tools diantaranya :

1. Check sheet

Digunakan untuk memudahkan pengumpulan data dan menetahui bagaimana suatu masalah sering terjadi (Gaspersz, 2003).

2. Stratifikasi

Merupakan teknik pengelompokan data kedalam kategori tertentu (Tjiptono, 2001).

3. Diagram pareto

Digunakan untuk mengidentifikasi hal-hal atau kejadian-kejadian penting (Gaspersz, 2003).

4. Diagram sebab-akibat

Digunakan untuk mengidentifikasi dan menganalisis suatu proses atau situasi dan menemukan kemungkinan penyebab suatu masalah yang terjadi (Tjiptono, 2001).

5. Diagram tebar

Digunakan untuk mengetahui apakah antara dua variabel mempunyai hubungan (korelasi) yang saling mempengaruhi atau tidak (Tjiptono, 2001).

6. Histogram

Digunakan untuk menentukan masalah dengan memeriksa bentuk dispersi, nilai rata-rata, dan sifat dispersi (Tjiptono, 2001).

7. Control chart

Digunakan untuk menghilangkan variasi tidak normal melalui pemisahan variasi yang disebabkan oleh penyebab khusus (Gaspersz, 2003).

\section{Metode FMEA (Failure Mode and Effect Analyis)}

Metode FMEA (Failure Mode and Effect Analyis) adalah suatu prosedur terstruktur untuk mengidentifikasi dan mencegah sebanyak mungkin mode kegagalan (failure modes). Suatu mode kegagalan adalah apa saja yang termasuk dalam kecacatan/ kegagalan dalam desain, kondisi di luar batas spesifikasi yang telah ditetapkan, atau perubahan-perubahan dalam produk yang menyebabkan terganggunya fungsi dari produk itu. (Gaspersz, 2012).

Identifikasi kegagalan dapat dilakukan dengan caramemberikan penilaian pada permasalahan tersebut berdasarkan nilai severity, occurance dan detection sehingga diperoleh nilai risk priority number (RPN). Risk Priority Number (RPN) menentukan prioritas dari suatu kegagalan, penggunaan RPN hanya untuk meranking kegagalan dalam suatu proses.Nilai RPN dapat diperoleh dari perkalian Severity, Occurance, dan Detection.

$$
\text { RPN = Severity } \times \text { Occurance } \times \text { Detection (1) }
$$

\section{METODOLOGI PENELITIAN}

Penelitian ini dilakukan pada jam kerja efektif di PT. XYZ yang terletak dijalan raya sedati no. 97 gedangan sidoarjo. Untuk tahapan-tahapan pada penelitian ini digambarkan pada gambar 1 . 


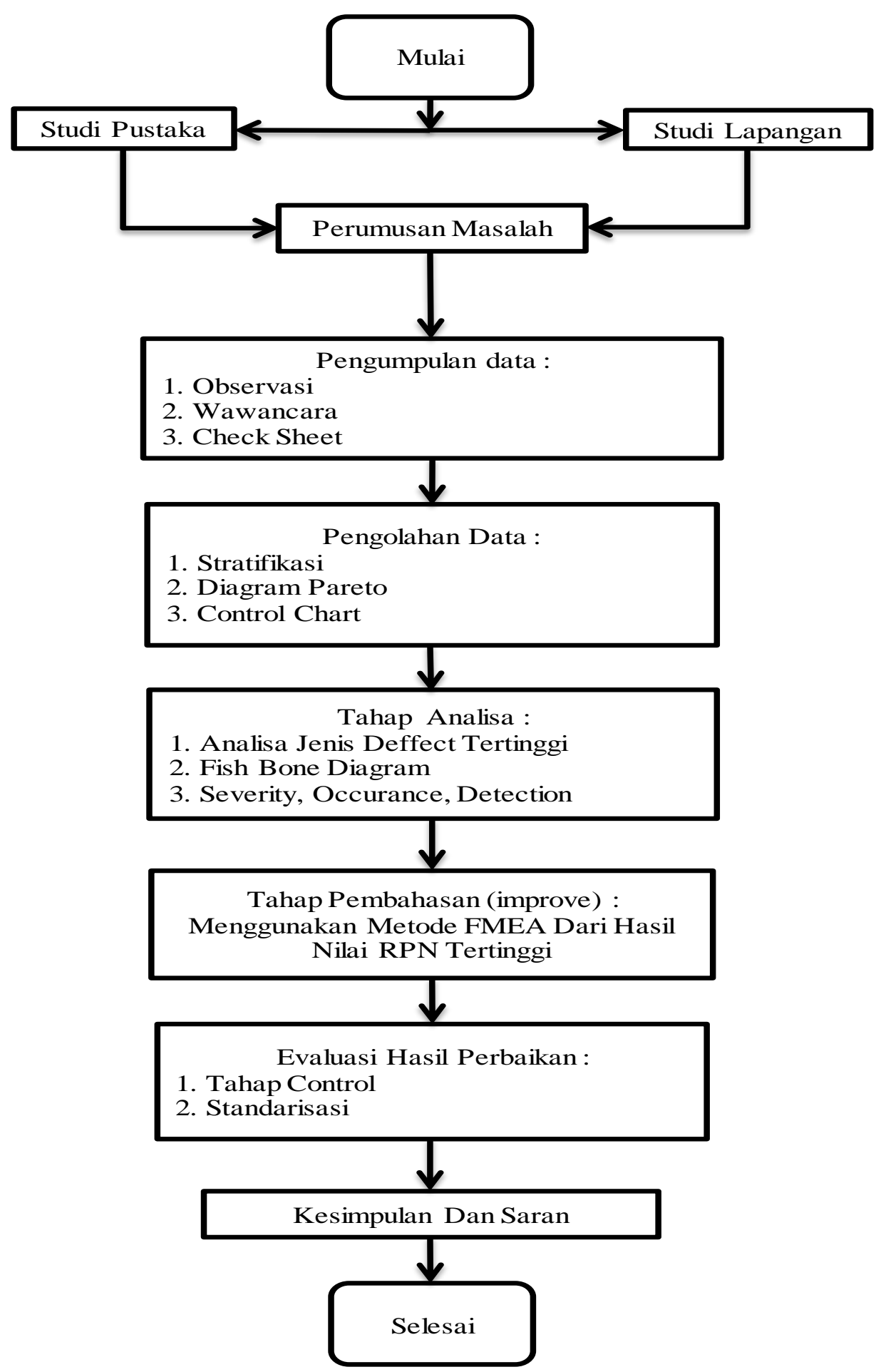

Gambar 1. Diagram Alir Penelitian

\section{A. Tahap Studi Lapangan dan Studi Pustaka}

Studi lapangan dilakukan secara langsung dengan mengamati kegiatan proses produksi di PT XYZ. Studi pustaka berguna untuk mengetahui penjelasan teori secara umum maupun khusus tentang metode yang digunakan dalam penelitian dan untuk menyelesaikan permasalahan yang ada. 


\section{B. Tahap Perumusan Masalah}

Perumusan masalah menjelaskan pertanyaan mengenai permasalahan yang ingin diselesaikan terhadap objek yang ditelitiserta menentukan tujuan dari proses pemecahan masalah dengan menggunakan studi literatur yang adasehingga tepat sasaran pada pokok permasalahan.

\section{Tahap Pengumpulan Data}

Tahap pencarian informasi berupa data primer (observasi, wawancara, data histori mesin) dan data sekunder (data yang diperoleh secara tidak langsung melalui perantara atau pihak lain dan digunakan untuk mendukung landasan teori dalam penelitian).

D. Tahap Pengolahan Data

Tahap awal dilakukan pengumpulan data menggunakan check sheet, dari data hasil check sheetakan dilakukan stratifikasi yang bertujuan untuk mengelompokkan data jenis rejectkemudiandilakukan analisa pareto untuk dapat menentukan tindakan pada penyebab utama masalah yang sedang terjadi. Setelah mengetahui jenis reject maka selanjutnya akan dibuat control chart untuk memantau terus menerus sehingga tidak ada variasi penyebab khusus dan hanya ada variasi penyebab umum.

\section{E. Tahap Analisa Hasil}

Tahapan analisa menggunakan fishbone diagram untuk mengidentifikasi penyebab yang mempengaruhi tingginya reject selanjutnya menggunakan metode FMEA guna menentukan pontential failure yang menyebabkan tingginya reject.Tahap awal menentukan kriteria penilaian severity, occurance, dan detection dari beberapa mode kegagalan.

\section{F. Tahap Pembahasan}

Pada tahap pembahasan akan dilakukan tindakan perbaikan sesuai dengan analisa faktor penyebab dan hasil perhitungan nilai RPN tertinggi. Hasil RPN (Risk Priority Number) diperoleh dari perkalian nilai Severity, Occurrence, dan Detection untuk setiap mode kegagalan yang terjadi.

\section{G. Tahap Control dan Standarisasi}

Tahap pengontrolan dilakukan dengan cara melakukan evaluasi kinerja pada operator yang ada untuk mengetahui hal-hal yang menyimpang dalam proses produksi Sehingga pengoptimalan proses produksi dapat berjalan maksimal melalui Standart Operational Procedure (SOP).

\section{H. Tahap Kesimpulan dan Saran}

Pada tahap kesimpulan dan saran ini menjelaskan tentang hasil dari analisa dan pembahasan penelitian dan memberikan rekomendasi perbaikan untuk peningkatan kualitas produk.

\section{HASIL DAN PEMBAHASAN}

Tahap awal pengolahan data menggunakan check sheet untuk memilah-milah data kedalam kategori yang berbeda sehingga data mudah dipahami dan dapat dianalisa dengan mudah. Kumpulan data yang sudah didapatkan dari hasil check sheet akan dilakukan stratifikasi bertujuan untuk menguraikan dan mengklasifikasi jenis kecacatan dari proses nonwoven spunbond berdasarkan jenis reject produk kemudian dilakukan analisa pareto untuk dapat menentukan tindakan pada penyebab utama masalah yang sedang terjadi selanjutnya membuat control chart untuk dapat mengetahui apakah hasil proses produksi masih berada pada pengendalian atau tidak.

\section{A. Stratifikasi}

Pengelompokan dilakukan sesuai dengan jenis reject yang terjadiagar menjadi lebih sederhana dan mudah dimengerti, hasil stratifikasi ditunjukkan pada tabel 1 dan 2. 
Tabel 1. Tabel stratifikasi hasil produksi berdasarkan jenis reject

\begin{tabular}{|l|c|c|}
\hline \multicolumn{1}{|c|}{ Jenis Reject } & Jumlah Reject & $\%$ Reject \\
\hline Reject filament & 49 & 0.51 \\
Reject kain & 42 & 0.43 \\
Reject trim & 694 & 7.18 \\
Total & 785 & 8.12 \\
\hline
\end{tabular}

Tabel 2. Tabel stratifikasi hasil reject produksi berdasarkan warna produk

\begin{tabular}{|c|c|c|c|c|}
\hline No. & Warna & $\begin{array}{c}\text { Output Proses } \\
\text { (Roll) }\end{array}$ & Reject & \% Reject \\
\hline 1 & Pure White & 4203 & 348 & 8.28 \\
2 & Ivory Black & 5467 & 437 & 7.99 \\
\hline
\end{tabular}

Sumber: PT.XYZ

Dari tabel stratifikasi hasil produksi berdasarkan jenis reject diatas didapatkan jenis reject tertinggi ada pada jenis rejecttrim yaitu sebesar $7.18 \%$, jenis reject filament dan reject jenis kain masih dalam batas toleransi dengan persentase sebesar $0.51 \%$ dan $0.43 \%$.

\section{B. Diagram Pareto}

Digunakan untuk mengidentifikasi hal-hal atau kejadian-kejadian penting (Gaspersz, 2003).Adapun data persentase reject ditunjukkan pada gambar 1.

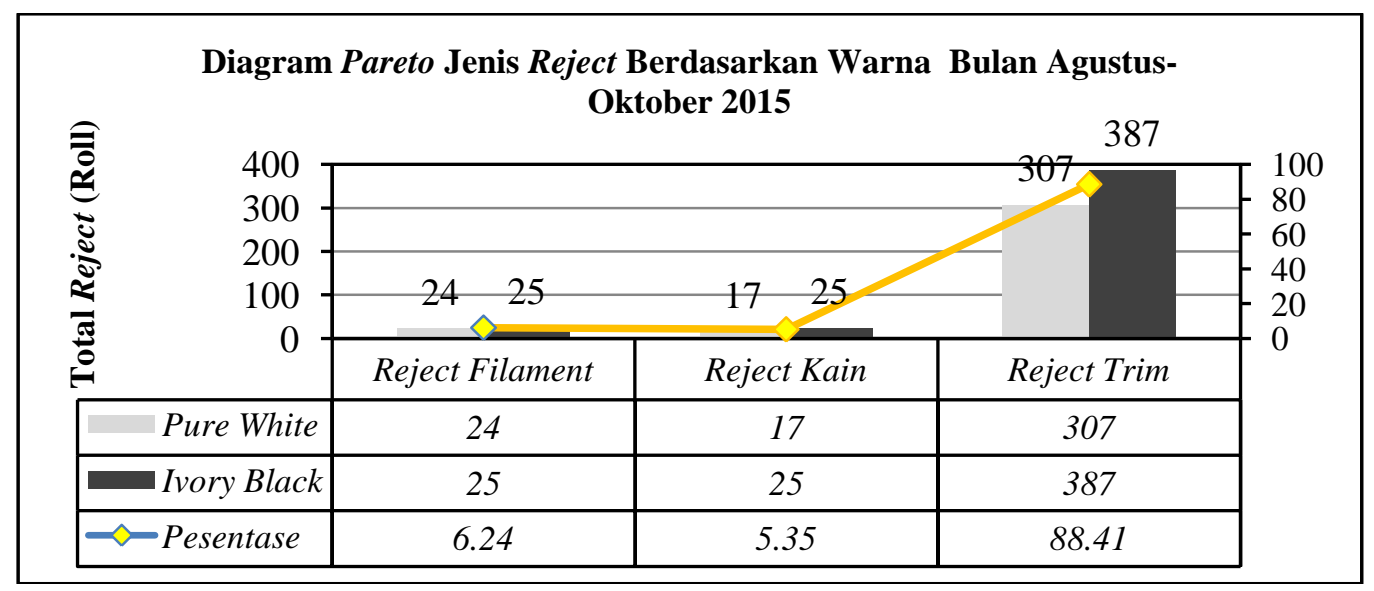

Gambar 2. Diagram pareto jenis reject berdasarkan warna produk Sumber: PT.XYZ

Diagram paretopada gambar 4.1 menunjukkan jenis reject yang paling tinggi adalah reject trim. Diketahui nilai reject trim $88.41 \%$ pada proses nonwoven spunbond, untuk dapat memberikan rekomendasi perbaikan maka penelitian ini akan difokuskan pada jenis reject trim.

\section{Control Chart}

Control chart digunakan untuk mengetahui apakah jenis rejecttrim hasil dari proses nonwoven spunbond dari hasil diagram pareto yang memfokuskan pada jenis reject masih dalam batas-batas pengendalian atau tidak. Adapun hasil control chart reject jenis trim dari proses produksi dapat ditunjukan pada gambar 2 . 


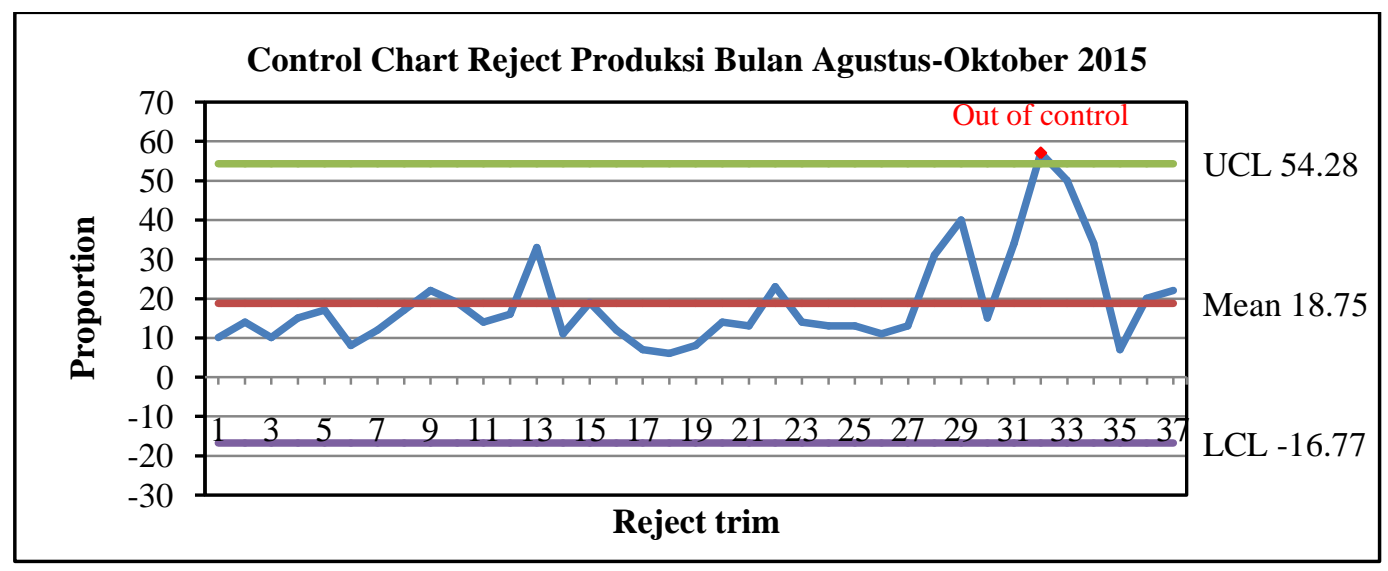

Gambar 3. Control Chart reject trim proses produksi

Sumber: PT. XYZ

Dari control chart pada gambar 2 diketahui jenis reject trim tidak terkendali, dikarenakan masih ada 1 data yang melebihi UCL dari total 37 data yang dianalisa. Data yang melebihi batas kendali atas tersebut berada pada poin 32 dengan nilai produk reject sebesar 57, sedangkan beberapa data yang dianalisa dalam keadaan terkendali belum melewati batas UCL (54.28) dan LCL (-16.77).

Setelah data yang out of control dihilangkan maka data reject trim dianalisa kembali, sehingga didapatkan data reject trim berada pada batas kendali. Tetapi nilai proportion dari reject trim sebesar $7.18 \%$ dikategorikan masih cukup tinggi dari pemakaian material yaitu sebesar 5\%. Data jenis reject trim yang berada dalam batas pengendalian terlihat pada gambar 3 .

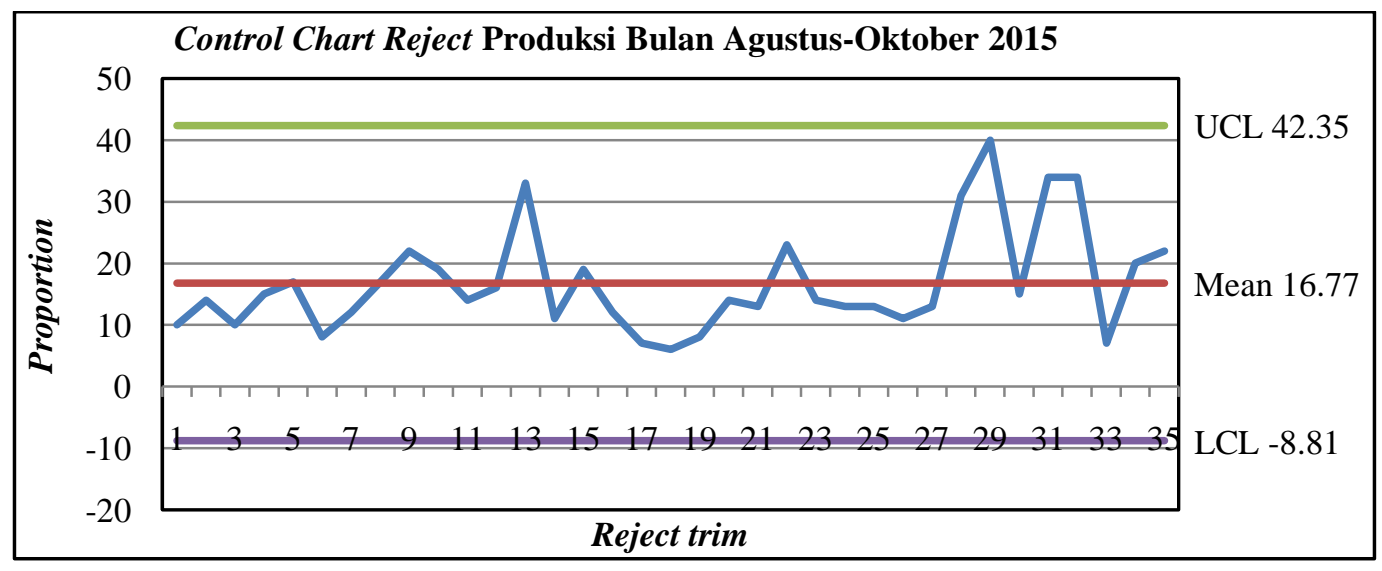

Gambar 4. Control Chart reject trim proses produksi

Sumber: PT. XYZ

\section{Fishbone Diagram}

Selanjutnya analisa mengenai penyebab tingginya reject trim dengan fishbone diagram bertujuan untuk mengetahui beberapa penyebab yang mempengaruhi tingginya reject padaproses nonwoven spunbond. Adapun hasil analisa reject trim dengan fishbone diagram ditunjukkan pada gambar 4. 


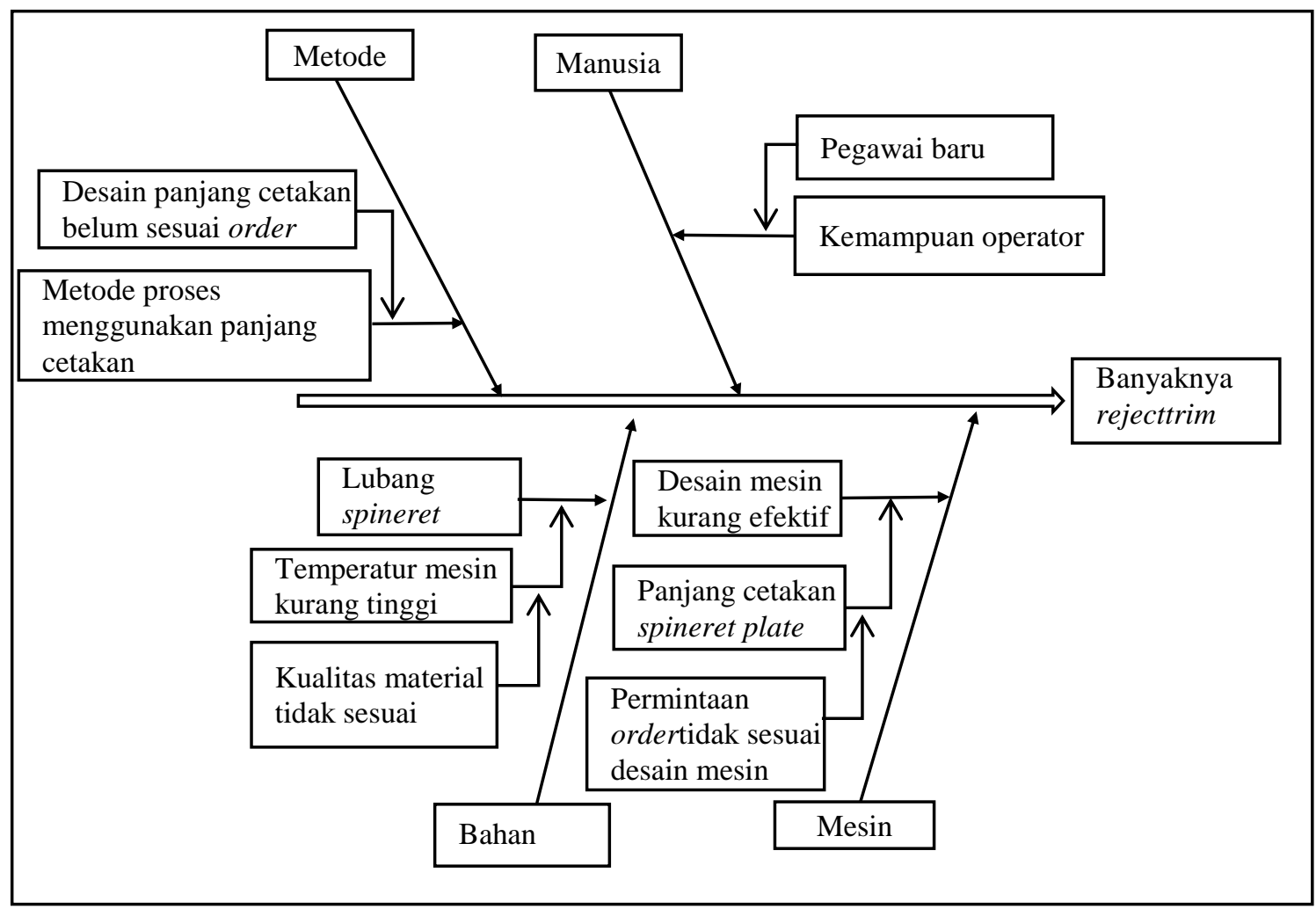

Gambar 5. Fishbone diagram reject trim

Sumber : Hasil observasi PT. XYZ

Pada gambar 4 diagram analisa sebab akibat dari tulang ikan banyaknya reject trim disebabkan oleh beberapa faktor yaitu:

1. Faktor manusia

Pegawai baru menjadi akar masalah jika dilihat dari diagram tulang ikan diatas. Sebab tidak memiliki skill dan pengalaman dibandingkan dengan operator lama, sehingga kemampuan pengoperasian dan setting mesin yang kurang bagus akan menimbulkan beberapa masalah pada proses produksi.

2. Faktor mesin

Banyaknya order yang bervariasi menjadi akar masalah jika dilihat dari segi mesin, karena mesin yang digunakan mempunyai panjang cetakan sesuai merek dan type mesin lama sehingga desain mesin yang lebih sesuai dengan order tertentu sangat diperlukan.

3. Metode

Metode yang digunakan masih menggunakan panjang cetakan yang lama dengan mengacu pada merek dan type mesin lama.

4. Faktor Material

Faktor kualitas material yang tidak sesuai menyebabkan material susah meleleh sehingga masih ada kerak dari sisa material yang mengakibatkan tersumbatnya cetakan spineret.

Setelah dilakukan analisa mengenai penyebab tingginya reject trim dengan fishbone diagram padaproses nonwoven spunbond selanjutnya menggunakan metode FMEA guna menentukan potential failure yang menyebabkan tingginya reject trim tahap awal yaitu menentukan kriteria penilaian SOD (severity, occurance, dan detection)dari beberapa mode kegagalan. 


\section{E. Severity}

Severity merupakan langkah awal untuk menganalisa resiko suatu penilaian tingkat keparahan dari keseriusan efek yang ditimbulkan dari mode kegagalan (failure mode).Adapun tabel kriteria penilaian untuk severity ditunjukkan pada tabel 3.

Tabel 3. Kriteria dan penilaian untuk severity

\begin{tabular}{|l|c|}
\hline \multicolumn{1}{|c|}{ Failure Mode and Effect Analysis (FMEA) } & Ranking \\
\hline Proses produksi terhenti Severity & 10 \\
Berhentinya proses produksi didahului tanda (alarm berbunyi) & 9 \\
Mengakibatkan gangguan pada mesin & 8 \\
Mesin dapat beroprasi tetapi sebagian komponen sudah tidak & 7 \\
berfungsi & 6 \\
Mengakibatkan gangguan pada komponen mesin & 5 \\
Mesin dan komponen beroprasi tetapi tidak maksimal & 4 \\
Mesin dan komponen memerlukan perbaikan & 3 \\
Terdapat efek secara langsung tetapi bersifat terbatas & 2 \\
Efek yang ditimbulkan tidak terjadi secara langsung & 1 \\
Bentuk gangguan yang terjadi tidak memiliki efek & \\
\hline
\end{tabular}

\section{F. Occurance}

Occurance menunjukkan penilaian tingkat keseringan suatu masalah yang ditimbulkan karena mode kegagalan.Adapun tabel kriteria penilaian untuk occurance ditunjukkan pada tabel 4.

Tabel 4.Kriteria dan penilaian untuk occurance

\begin{tabular}{|l|c|c|}
\hline \multicolumn{1}{|c|}{ Kemungkinan Terjadi } & $\begin{array}{c}\text { Failure Mode and Effect Analysis } \\
\text { (FMEA)Kriteria Occurance }\end{array}$ & Ranking \\
\hline Bahaya tidak bisa dihindari & $\geq 100 \times$ terjadi gangguan setiap 3 bulan & 10 \\
Diatas batas control & $90 \times$ terjadi gangguan setiap 3 bulan & 9 \\
Sangat tinggi & $80 \times$ terjadi gangguan setiap 3 bulan & 8 \\
Tinggi & $70 \times$ terjadi gangguan setiap 3 bulan & 7 \\
Terulang kejadian sama & $60 \times$ terjadi gangguan setiap 3 bulan & 6 \\
Sedang & $50 x$ terjadi gangguan setiap 3 bulan & 5 \\
Dibawah batas kontrol & $40 \times$ terjadi gangguan setiap 3 bulan & 4 \\
Sesekali terjadi & $30 x$ terjadi gangguan setiap 3 bulan & 3 \\
Rendah & $20 x$ terjadi gangguan setiap 3 bulan & 2 \\
Sangat rendah & $10 x$ terjadi gangguan setiap 3 bulan & 1 \\
\hline
\end{tabular}

\section{G. Detection}

Detection merupakan alat kontrol yang digunakan untuk mendeteksi kriteria yang ditimbulkan dari metode-metode yang diterapkan dari mode kegagalan.kriteria penilaian dari detection ditunjukkan pada tabel 5. 
Tabel 5. Kriteria dan penilaian untuk detection

\begin{tabular}{|l|l|c|}
\hline \multicolumn{1}{|c|}{ Deteksi } & \multicolumn{1}{|c|}{\begin{tabular}{c}
\multicolumn{1}{c|}{ Dailure Modection } \\
Tidak pasti
\end{tabular}} & Gangguan tidak dapat terdeteksi \\
Sangat jarang & Gangguan sangat jarang terdeteksi & 10 \\
Jarang & $\begin{array}{l}\text { Gangguan jarang terdeteksi } \\
\text { Kemampuan sumberdaya dan alat untuk mendeteksi }\end{array}$ & 7 \\
Sangat rendah & $\begin{array}{l}\text { Sengat rendah } \\
\text { sangriteria }\end{array}$ & 7 \\
Rendah & $\begin{array}{l}\text { Kemampuan sumberdaya dan alat untuk mendeteksi } \\
\text { rendah }\end{array}$ & 6 \\
Cukup & $\begin{array}{l}\text { Kemampuan sumberdaya dan alat untuk mendeteksi } \\
\text { cukup }\end{array}$ & 5 \\
Cukup tinggi & $\begin{array}{l}\text { Kemampuan sumberdaya dan alat untuk mendeteksi } \\
\text { cukup tinggi }\end{array}$ & 4 \\
Tinggi & $\begin{array}{l}\text { Kemampuan sumberdaya dan alat untuk mendeteksi } \\
\text { tinggi }\end{array}$ & 3 \\
Sangat tinggi & $\begin{array}{l}\text { Kemampuan sumberdaya dan alat untuk mendeteksi } \\
\text { sangat tinggi }\end{array}$ & 2 \\
Hampir pasti & $\begin{array}{l}\text { Kemampuan absolute dari sumberdaya dan alat } \\
\text { untuk mendeteksi }\end{array}$ & 1 \\
\hline
\end{tabular}

Setelah kriteria penilaian SOD (severity, occurance, dan detection) dilakukan selanjutnya menentukan potential failure yang menyebabkan tingginya reject trim. Berikut potential failure dan hasil penilaian Severity, Occurrence, dan Detection dapat dilihat pada tabel 6 .

Tabel 6.Potential failure dan hasil penilaian SOD

\begin{tabular}{|c|c|c|c|c|c|c|c|}
\hline $\begin{array}{l}\text { potensial } \\
\text { failure } \\
\text { mode }\end{array}$ & efek & Severity & penyebab & Occurance & $\begin{array}{c}\text { deteksi } \\
\text { kegagalan }\end{array}$ & Detection & $\begin{array}{l}\text { Nilai } \\
\text { RPN }\end{array}$ \\
\hline $\begin{array}{l}\text { Terdapat } \\
\text { bintik } \\
\text { polimer }\end{array}$ & $\begin{array}{l}\text { terdapat } \\
\text { efek tetapi } \\
\text { bersifat } \\
\text { terbatas }\end{array}$ & 3 & $\begin{array}{l}\text { temperatur } \\
\text { chiller } \\
\text { tidak } \\
\text { tercapai }\end{array}$ & 2 & $\begin{array}{l}\text { pengecekan } \\
\text { oleh } \\
\text { maintenace }\end{array}$ & 1 & 6 \\
\hline $\begin{array}{l}\text { hole } \\
\text { continue }\end{array}$ & $\begin{array}{l}\text { penggantian } \\
\text { komponen } \\
\text { (take out } \\
\text { spineret) }\end{array}$ & 8 & $\begin{array}{l}\text { adanya } \\
\text { kotoran } \\
\text { menempel } \\
\text { dispineret }\end{array}$ & 3 & $\begin{array}{l}\text { pengecekan } \\
\text { oleh } \\
\text { operator }\end{array}$ & 1 & 24 \\
\hline
\end{tabular}


Tabel 6. Potential failure dan hasil penilaian SOD...(Lanjutan)

\begin{tabular}{|c|c|c|c|c|c|c|c|}
\hline $\begin{array}{c}\text { potensial } \\
\text { failure } \\
\text { mode }\end{array}$ & efek & Severity & penyebab & Occurance & $\begin{array}{c}\text { deteksi } \\
\text { kegagalan }\end{array}$ & Detection & $\begin{array}{l}\text { Nilai } \\
\text { RPN }\end{array}$ \\
\hline $\begin{array}{l}\text { lebar } \\
\text { kain } \\
\text { berlebih }\end{array}$ & $\begin{array}{l}\text { mesin dan } \\
\text { komponen } \\
\text { berjalan } \\
\text { tapi tidak } \\
\text { maksimal }\end{array}$ & 5 & $\begin{array}{l}\text { panjang } \\
\text { order } \\
\text { tidak } \\
\text { sesuai } \\
\text { cetakan } \\
\text { spineret }\end{array}$ & 6 & $\begin{array}{l}\text { pengecekan } \\
\text { oleh } \\
\text { operator }\end{array}$ & 1 & 30 \\
\hline $\begin{array}{l}\text { sobek } \\
\text { samping }\end{array}$ & $\begin{array}{l}\text { adanya } \\
\text { gangguan } \\
\text { pada } \\
\text { conveyor }\end{array}$ & 4 & $\begin{array}{l}\text { benang } \\
\text { filament } \\
\text { putus }\end{array}$ & 3 & $\begin{array}{l}\text { pengecekan } \\
\text { oleh } \\
\text { operator }\end{array}$ & 1 & 12 \\
\hline
\end{tabular}

Berdasarkan perhitungan nilai RPN masing-masing mode kegagalan, diperoleh nilai RPN tertinggi yaitu pada mode kegagalan lebar kain berlebih dengan nilai RPN 30 . Pada mode kegagalan lebar kain yang berlebih karena disebabkan oleh permintaan order yang tidak sesuai dengan desain mesin, maka harus ada tindakan perbaikan atau perubahan desain untuk menekan reject trim yang disebabkan lebar kain yang berlebih. Akan tetapi untuk mode kegagalan yang lainnya juga harus dilakukan pembenahan untuk dapat meningkatkan kualitas dan kuantitas produksi.

\section{H. Rekomendasi Perbaikan}

Berdasarkan pengolahan data yang sudah dilakukan, maka rekomendasi perbaikan yang dapat dilakukan terlihat pada tabel 7 .

Tabel 7. Rekomendasi yang diberikan berdasarkan nilai RPN tertinggi

\begin{tabular}{|c|c|c|c|}
\hline $\begin{array}{c}\text { Mode } \\
\text { Kegagalan }\end{array}$ & Efek & Penyebab & Rekomendasi Perbaikan \\
\hline $\begin{array}{l}\text { Lebar kain } \\
\text { berlebih (nilai } \\
\text { RPN) }=30\end{array}$ & $\begin{array}{l}\text { Mesin dan komponen } \\
\text { berjalan tapi tidak } \\
\text { maksimal dan tidak } \\
\text { efisien pada } \\
\text { penggunaan material }\end{array}$ & $\begin{array}{l}\text { Panjang } \\
\text { order tidak } \\
\text { sesuai } \\
\text { cetakan } \\
\text { spineret }\end{array}$ & $\begin{array}{l}\text { Membuat alat bantu sebagai sarana } \\
\text { untuk menekan reject trim } \\
\text { menggunakan penutup plat tembaga } \\
\text { atau kuningan untuk menutup sisi } \\
\text { samping agar sesuai dengan } \text { order } \\
\text { yang ada. }\end{array}$ \\
\hline $\begin{array}{l}\text { Hole continue } \\
\text { (nilai RPN) }= \\
24\end{array}$ & $\begin{array}{l}\text { Penggantian } \\
\text { komponen (take out } \\
\text { spineret) }\end{array}$ & $\begin{array}{l}\text { Adanya } \\
\text { kotoran } \\
\text { menempel } \\
\text { dispineret }\end{array}$ & $\begin{array}{l}\text { Membuat SOP (standart operational } \\
\text { procedure) dan chek sheet untuk } \\
\text { menjadwalkan pergantian filter secara } \\
\text { berkala. }\end{array}$ \\
\hline $\begin{array}{l}\text { Sobek } \\
\text { samping (nilai } \\
\text { RPN) }=12\end{array}$ & $\begin{array}{l}\text { Adanya gangguan } \\
\text { pada konveyor }\end{array}$ & $\begin{array}{l}\text { Benang } \\
\text { filament } \\
\text { putus }\end{array}$ & $\begin{array}{l}\text { Melakukan pemantauan secara } \\
\text { berkala dan perawatan pada mesin } \\
\text { chiller. }\end{array}$ \\
\hline $\begin{array}{l}\text { Terdapat } \\
\text { bintik polimer } \\
\text { (nilai RPN) }= \\
6\end{array}$ & $\begin{array}{l}\text { Terdapat efek tetapi } \\
\text { bersifat terbatas pada } \\
\text { konveyor }\end{array}$ & $\begin{array}{l}\text { Temperatur } \\
\text { chiller } \\
\text { tidak } \\
\text { tercapai }\end{array}$ & $\begin{array}{l}\text { Melakukan pemantauan secara } \\
\text { berkala dan perawatan pada mesin } \\
\text { chiller. }\end{array}$ \\
\hline
\end{tabular}




\section{KESIMPULAN DAN SARAN}

\section{A. Kesimpulan}

Setelah dilakukan pengambilan dan pembahasan data reject pada proses nonwoven spunbond maka didapatkan beberapa kesimpulan yaitu :

1. Jenis reject tertinggi dari proses nonwoven spunbond adalah jenis reject trim sebesar 7.18\%. diperoleh beberapa faktor penyebab jenis reject trim yaitu :
a. Pegawai baru.
b. Banyaknya order yang bervariasi.
c. Metode yang digunakan mengacu pada merk dan type mesin lama.
d. Kualitas material yang ada tidak sesuai dengan mesin.
e. Desain mesin yang tidak sesuai order.

2. Adapun tindakan perbaikan yang dilakukan untuk mengatasi faktor yang berpengaruh pada kualitas produk adalah sebagai berikut :

a. Membuat alat bantu sebagai sarana untuk menekan reject trim.

b. Menekankan pengoptimalan proses produksi melalui Standart Operational Procedure (SOP).

c. Tahap pengontrolan dilakukan dengan cara melakukan evaluasi kinerja pada operator yang ada untuk mengetahui hal-hal yang menyimpang dalam proses produksi.

\section{B. Saran}

1. Pada penelitian selanjutnya diharapkan bisa meningkatkan kualitas proses dengan metode-metode lain yang nantinya bisa dibandingkan sehingga memperoleh hasil yang lebih baik.

2. Hasil dari usulan perbaikan dapat diimplementasikan oleh PT. XYZ, lebih baik dilakukan uji coba terlebih dahulu agar pada saat permintaan naik kejadian yang tidak terduga bisa diatasi dengan baik.

\section{DAFTAR PUSTAKA}

[1] Gaspersz, Vincent. (2003). Metode Analisis Untuk Peningkatan Kualitas. Jakarta: Gramedia Pustaka Utama.

[2] Gaspersz, Vincent. (2012). All-In-One Management Toolbook Contoh Aplikasi Dan Industri Modern. Bogor: Tri-Al-Bros.

[3] Tjiptono, Fandy, Anastasia Diana. (2001). Total Quality Management (TQM). Yogyakarta: Andi. 